\title{
Reestruturação Produtiva e Variabilidade do Trabalho: Uma Abordagem da Ergonomia
}

\author{
Júlia Issy Abrahão ${ }^{1}$ \\ Universidade de Brasília
}

\begin{abstract}
RESUMO - Este artigo é um estudo teórico que discute a pertinência de incorporar no escopo de um projeto de automação/ informatização dos postos de trabalho o conceito de variabilidade. Neste sentido, ressalta a contribuição da ergonomia ao processo de introdução de novas tecnologias que, além de modificar a natureza do trabalho, a produtividade afeta, muitas vezes a saúde do trabalhador. A variabilidade do trabalho, decorrente da diferença entre a prescrição e a realidade, pode ser compreendida considerando: (a) as características do trabalhador, ressaltando a noção de variabilidade inter e intra individual, e (b) a organização do trabalho, onde destaca-se a variabilidade dos equipamentos/materiais e dos procedimentos. Ao considerar as variabilidades na concepção de um projeto ou na situação de inovação tecnológica, propicia-se uma melhoria das condições de trabalho, flexibilizando e reduzindo a polarização imposta pelo trabalho prescrito, cuja referência é, geralmente, um operário médio, bem treinado, que trabalha em um posto estável.
\end{abstract}

Palavras-chave: ergonomia; variabilidade; novas tecnologias

\section{Productive Restructuring and Variability in the Work: Ergonomics Approach}

\begin{abstract}
This theoretical paper discusses de appropriateness of including the concept of variability into projects of automating work stations. It underlines the contribution of ergonomics to the process of introducing new technologies, which not only modify the nature of the work but frequently the health of the worker as well. The variability of work, a consequence of the difference between prescribed norms and reality, may be understood based on (a) the characteristics of the worker, stressing the notion of inter- and intrapersonal variability, (b) the organization of the work process, stressing the variability of equipment, materials and procedures. By taking variability into account when elaborating a project or a situation of technological innovation, it renders favourable improvement in working conditions due to flexibility and reduction of impositions of prescribed work norms, which usually are based on a 'mean' worker, well trained and working under stable conditions.
\end{abstract}

Key Words: ergonomics; variability; new tecnologies

Este artigo tem como objetivo conduzir uma reflexão, na perspectiva da ergonomia, sobre a questão da variabilidade dos homens, dos equipamentos e da matéria-prima inserida no contexto de trabalho.

As novas tecnologias e seus impactos no trabalho humano têm sido abordados sob vários ângulos, variando conforme as áreas do conhecimento e a natureza da problemática analisada. A ergonomia tem sido solicitada, cada vez mais, a atuar na análise de processos de reestruturação produtiva, sobretudo, no que se refere às questões relacionadas à caracterização da atividade e à inadequação dos postos de trabalho, em especial em situações de mudanças ou de introdução de novas tecnologias.

A caracterização da atividade é um elemento fundamental para instrumentalizar o desempenho dos sistemas de produção, objetivando atingir um funcionamento estável em quantidade e qualidade. A inadequação dos postos de trabalho, à população de trabalhadores, constitui um proble-

1 Endereço: SQS 202, Bloco H, Apto 602, CEP: 70.232-080 - Brasília DF. E-mail: abrahao@unb.br ma social importante com reflexos nas questões de requalificação, saúde e produtividade. Segundo Wisner (1987), um grande número de pessoas encontra-se rejeitada pelo sistema produtivo ou situadas à sua margem em decorrência da reestruturação produtiva, que exige um novo perfil do trabalhador. Vale ressaltar que esta reestruturação nem sempre considera a variabilidade do trabalho e o trabalhador como o sujeito do processo de reestruturação produtiva.

Abrahão (1996) afirma que, atualmente, com a automação nos setores secundários e terciários da economia e com a introdução da robótica, os setores produtivos começam a perceber cada vez mais, que os meios técnicos determinados pela organização do trabalho devem ser adaptados às especificidades do funcionamento humano.

O impacto das inovações tecnológicas sobre o modo de produção incide tanto nas relações de troca, quanto nas relações de produção propriamente ditas. Tais inovações alteram as formas de cooperação influindo diretamente na atividade humana, na matéria prima que se aplica o trabalho e nos meios e instrumentos utilizados (Machado, 1994). Neste sentido, a ergonomia vem trabalhando, de forma sistemática, no estudo da introdução destas novas tecnologias, demonstrando a transformação do conteúdo e da natureza do 


\section{J.I. Abrahão}

trabalho, bem como as consequiências destas mudanças na saúde dos sujeitos e na eficácia das organizações.

As modificações relativas à natureza da tarefa, em particular, pelos novos padrões tecnológicos têm se concretizado através da automação das tarefas manuais, repetitivas e monótonas, onde o papel reservado ao homem é, sobretudo, voltado para o controle e a manutenção do processo. Assim, nos processos de produção contínua, por exemplo, a tarefa do operador é transformada, e ele assume o papel de supervisão e controle dos processos.

Nesta nova configuração, o operador é distanciado ainda mais do objeto de seu trabalho. A centralização dos comandos e dos dispositivos, bem como o desenvolvimento dos meios de comunicação para o gerenciamento à distância, tem como resultado a modificação da natureza da atividade humana, exigindo uma forte mobilização mental para a compreensão do trabalho.

Nesta perspectiva, podemos inferir que as novas tecnologias têm imposto cada vez mais exigências de natureza cognitiva ao trabalhador. Estas se configuram por meio de diferentes processos decisórios envolvidos no controle do processo de trabalho e na resolução de problemas dele resultante.

Assim, a ergonomia, reconhecida inicialmente na luta pela saúde do trabalhador contra os acidentes e pela melhoria das condições de trabalho, trouxe contribuições significativas para a adequação do sistema técnico, propiciando vantagens econômicas e financeiras quando da introdução das novas tecnologias (Wisner, 1996). Na prática, em ergonomia, um conjunto de conhecimentos é estruturado para responder a diferentes demandas.

As contribuições da ergonomia, na introdução de melhorias nas situações de trabalho, se dão pela via da ação ergonômica que busca compreender as atividades dos indivíduos em diferentes situações de trabalho com vistas à sua transformação. Assim, o foco de ação é a situação de trabalho inserida em um contexto sociotécnico, a fim de desvendar as lógicas de funcionamento e suas conseqüências, tanto para a qualidade de vida no trabalho, quanto para o desempenho da produção.

Segundo Wisner (1994a), “...uma das características mais notáveis dos seres vivos é a diversidade de suas reações numa dada situação" (p.19). Numa mesma população, estas variam consideravelmente. Podemos, então, esperar uma grande diversidade nos níveis de tolerância às dificuldades das situações de trabalho.

Todo indivíduo chega ao trabalho com seu capital genético, remontando o conjunto de sua história e as marcas acumuladas na vida. Traz seu modo de vida, seus costumes pessoais, seus aprendizados. Este conjunto de fatores influencia a forma como são abordadas as situações de trabalho com as quais este indivíduo é cotejado.

As situações variam, pois cada uma é singular, sendo caracterizada pelas diferenças individuais que são confrontadas aos mesmos objetivos e meios de trabalho. Assim, elas se configuram como situações diferenciadas, depen- dendo do indivíduo, ou seja, suas experiências, sua história e sua formação.

Nesta perspectiva, a singularidade das situações de trabalho, são permeadas pelo cotejamento das características dos indivíduos com os objetivos da produção e com o meio social e tecnológico que lhe é oferecido para a consecução destes objetivos.

Para as situações de trabalho em sua totalidade e dimensões, a ergonomia utiliza uma metodologia própria de intervenção - $\mathrm{a}$ análise ergonômica do trabalho que tem como fio condutor a atividade - o fazer do trabalhador inserido em um contexto real, objetivando apreender o trabalho efetivamente realizado, ou seja, como o homem se comporta para executar o que lhe é imposto pela organização do trabalho.

Uma das contribuições importantes da análise da atividade reside no fato das ações estarem sempre inscritas em um contexto, tornando-se impossível compreendê-las fora dele (Wisner, 1996).

Ao traçarmos um paralelo entre a noção de atividade adotada pela ergonomia e a perspectiva da teoria da atividade de Leontiev (1964), verificamos similitudes, considerando que Leontiev, não atribui à atividade um caráter estático, ao contrário, ele ressalta o caráter dinâmico da atividade, considerando-a portanto, como um processo em constante desenvolvimento. Este desenvolvimento não é linear, tampouco direto, e sim, irregular e descontínuo. Tais características demonstram que a atividade está inscrita em sua própria história, na medida em que resíduos de atividades anteriores permanecem inseridos nas novas, apontando assim, para a importância da análise histórica do desenvolvimento da atividade para a compreensão da situação atual. Emerge então, o enfoque adotado pela ergonomia, da importância de se conhecer a experiência anterior dos operadores, com o intuito de possibilitar a interação entre as antigas e as novas atividades.

A integração do conceito de atividade nos projetos de situações de trabalho implica em reconhecer que estas devem ser concebidas considerando a diversidade da população de trabalhadores, bem como as características a ela inerentes, ou seja, a variabilidade.

Reconhecer e compreender a variabilidade inter e intra individual nas diferentes etapas de um projeto industrial/ organizacional possibilita a introdução de elementos flexíveis desde a concepção como, por exemplo, a valorização de um saber constituído ao longo do tempo, incorporado na experiência do trabalhador.

Ao considerarmos a diversidade da formação, da aprendizagem e da experiência contribuímos para a implantação de suportes que favorecem o desenvolvimento continuado das competências, possibilitando assim, atender às necessidades da reestruturação do trabalho que exigem do trabalhador de qualquer idade, em diferentes níveis de formação conhecimentos e habilidades para acompanhar estas mudanças, evitando a exclusão de pessoas portadoras de experiências valiosas no desenvolvimento do processo de reestruturação do trabalho. 


\section{A Noção de Variabilidade}

As empresas, na organização do processo de trabalho, planejam e fornecem os meios necessários à produção, na medida em que dividem tarefas, estabelecem critérios, normas e regras definindo, assim, os objetivos a serem alcançados no processo de trabalho. Muitas vezes, adotam como referência um pressuposto herdado de Taylor, cuja máxima reside na concepção de um "operário médio", bem treinado e que trabalha em um posto estável (Wisner, 1987). Porém, o que se observa no cotidiano é que esta estabilidade não corresponde à realidade. Os estudos demonstram uma diferença entre o que é previsto e o que é realizado, entre o desejável e o real, pois nas situações de trabalho ocorrem variações freqüentes, em decorrência de vários fatores. Dentre eles, vale ressaltar a organização do trabalho bem como aqueles relacionados às características do trabalhador.

Na perspectiva da organização do trabalho, devem ser incluídos desde os materiais, os equipamentos e os procedimentos, até a gestão dos incidentes. Quanto às características do trabalhador, a literatura aponta as fontes de variabilidade do indivíduo como as de natureza inter e intra individuais, levando-se em conta os aspectos físicos, psíquicos e cognitivos, neles inseridos, a experiência como história das representações mentais, o envelhecimento como história biológica e outras intrinsecamente ligadas à história do trabalho. É neste contexto do real que a atividade realmente ocorre e não naqueles previstos, malgrado os esforços da organização na sua tentativa de estabilização do processo ou ainda da normatização.

A atividade compreende vários artefatos tais como instrumentos, signos, procedimentos, máquinas, métodos, regras e formas de organização do trabalho. Entretanto, uma das características importantes destes artefatos é o seu papel de mediação entre o trabalhador e o objeto do trabalho (Wisner, 1997; Rabardel, 1995 e Monoud, 1970).

A mediação entre o objeto e objetivo, segundo Engeström (1987), é estabelecida através de um terceiro elemento - artefato. Portanto, a relação entre o sujeito e o objeto tem como mediador os artefatos que podem ser instrumentais utilizados no processo de transformação, sejam eles, materiais ou intelectuais. Por exemplo, a relação entre o sujeito e o coletivo tem como mediador as regras que compreendem as normas explicitas ou implícitas, as convenções e as relações sociais no seio do coletivo. A relação entre o objeto e o coletivo tem como mediador a divisão de trabalho que qualifica a organização explicita e implícita em relação ao processo de transformação do objeto em produto. Cada um destes mediadores é constituído historicamente e de forma diferente.

Muitas vezes, os artefatos são criados e transformados durante o desenvolvimento da atividade e trazem em si uma cultura particular, resíduo histórico deste desenvolvimento. Assim sendo, a atividade constitui por si só o contexto significativo mínimo para a compreensão das ações de trabalho. Neste sentido, é possível que o objeto e o objetivo só se revelem no processo do fazer.
Nesta perspectiva, podemos constatar que na situação real de trabalho, a variabilidade está sempre presente e de forma estrutural. Este cenário é o espaço onde se confrontam as características do indivíduo, as exigências da produção e a organização do trabalho. Portanto, é necessário integrar estas variações de maneira a facilitar a qualidade de vida no trabalho e a favorecer, a contento, o funcionamento da produção.

Perrow (1967) e Wisner (1994a), em períodos distintos, ressaltam que a variabilidade das tarefas pode ser avaliada segundo o número de exceções verificadas para o funcionamento normal do sistema. Outro aspecto destacado pelos autores está relacionado ao grau de dificuldade que o trabalhador encontra, para identificar as alterações e variações dos parâmetros que ocorrem durante o processo de trabalho e que afetam o funcionamento do sistema. Estes fatos, na prática, têm grande importância para a ergonomia que, há muito tempo, tem se empenhado em demonstrar que as tarefas aparentemente mais monótonas e as estritamente organizadas exigem uma adaptação permanente dos trabalhadores às variações das máquinas e da matéria pri$m a$ (Wisner, 1994a, p.166). É por isto que os ergonomistas tendem a recomendar uma organização mais flexível, quando se fala na inserção de novas tecnologias, com o objetivo de permitir ao trabalhador responder adequadamente a essas variações no decorrer do seu trabalho.

A resposta dos operadores a esta variabilidade era entendida anteriormente como o afastamento do trabalho prescrito e, portanto, como um risco à qualidade da produção e aos equipamentos. Entretanto, com os avanços da psicologia cognitiva, este afastamento é hoje entendido como uma forma de gestão desta variabilidade. Wisner (1996) afirma que o operador constitui a todo momento, o problema que ele tem a resolver. Esta construção se apoia tanto nas variações da máquina, do ambiente, da matéria prima e das relações sociotécnicas, quanto nas competências do próprio operador.

A compreensão da competência dos trabalhadores está relacionada à sua capacidade de regulação, ou seja, gerir a variabilidade de acordo com as situações. Quanto maior a variabilidade das situações, menor a probabilidade de antecipação, exigindo assim, maior competência dos trabalhadores para a passagem de uma operação prescrita à uma ação situada (contextualizada). Esta competência possibilita, também, redefinir a atividade, favorecendo a reconstituição de situações anteriores por meio de reformulações, utilizando para isto recursos do próprio contexto como, por exemplo, o apelo à competência de outros trabalhadores, a elaboração de novos parâmetros para esta atividade ou, até mesmo, a utilização eventual de uma estratégia operatória antiga. Esta capacidade de regulação constitui uma competência, que é necessário considerar nas diferentes etapas de um projeto industrial ou organizacional, objetivando atingir um funcionamento que possibilite uma produção estável em quantidade e qualidade.

A análise ergonômica do trabalho permite identificar, por intermédio da observação do contexto real de trabalho, 


\section{J.I. Abrahão}

quais são as variáveis que o operador busca para compreender os problemas aos quais ele é confrontado e, desta forma, associar os processos cognitivos que ele mobiliza na execução do seu trabalho. Estes dados são fundamentais para a melhoria do dispositivo técnico, da organização e da formação.

Segundo Laville (1976/1977), o objetivo do estudo da atividade do trabalhador é conhecer as funções que este mobiliza e compreender as modalidades de utilização destas funções.

Os modelos que habitualmente são utilizados nas intervenções ergonômicas buscam estabelecer uma relação entre a atividade e a multiplicidade de fatores que a determina, ou seja, procuram integrar a atividade com estes fatores. Por exemplo, compreender como se processa a interrelação entre as características da população (variabilidade intra e inter-individual) com aquelas oriundas do contexto do trabalho (organização, tecnologia, gerenciamento, dentre outros).

Por que é importante considerar estas características no projeto, seja no momento da concepção ou da introdução de novas tecnologias? Em outros termos, para que deveria servir uma analise das características da população em um projeto industrial/organizacional?

Às vezes, o modo de funcionamento deteriorado de uma unidade é caracterizado pela multiplicidade e diversidade entre o prescrito (o que é estabelecido pela organização do trabalho) e o real (atividade). Perrow (1967), sociólogo americano da área organizacional, realizou um estudo onde, já naquela época, demonstrou a importância da variabilidade das atividades nas contingências da organização do trabalho, bem como a importância das empresas considerarem este elemento nas etapas de um projeto industrial/ organizacional.

Os erros da produção atribuídos, muitas vezes, à incompetência dos trabalhadores, são frutos do desconhecimento da empresa sobre as reais situações do trabalho, assim como à variabilidade das atividades às quais os operadores são confrontados. Neste enfoque, a literatura é consensual e aponta para a importância de se considerar, nas diferentes etapas de um projeto industrial/organizacional, as características da população e as competências exigidas para cada situação a fim de prevenir o risco de um funcionamento técnico de forma degradada, comprometendo as competências já estabelecidas.

A atividade de trabalho, entendida neste contexto, como o modo segundo o qual cada um dos indivíduos se relaciona com os objetivos propostos, com a organização do trabalho e com os meios que ele dispõe para realizá-los. Este modo configura um conjunto sempre singular de determinações, denominado modo operatório, ou seja, seqüências de ação, de gestos, de sucessivas buscas e tratamento de informações, de comunicações verbais ou gráficas e de identificação de incidentes. Enfim, significa a mobilização de suas representações mentais, de suas estratégias operatórias e das suas competências. Este fazer, reafirmamos, é o que caracteriza a atividade efetivamente realizada pelo sujeito.
Neste sentido, a atividade atua como um agente integrador desta multiplicidade de fatores no processo de trabalho, em especial, da integração das características diferenciadas e variáveis.

Portanto, ao considerar a variabilidade, busca-se um equilíbrio entre as características dos sujeitos e o seu ambiente de trabalho visando obter os resultados esperados pela produção, dentro das melhores condições possíveis. Segundo Weill-Fassina (1990), o trabalho é considerado uma conduta finalística que o sujeito apreende e é dirigida por uma meta cuja consecução deve se adaptar às exigências do ambiente material e social.

A análise ergonômica do trabalho possibilita o estabelecimento das relações entre a atividade e os seus diferentes níveis de determinantes.

Como integrar a noção de variabilidade, se considerarmos a singularidade de cada situação estudada, a variabilidade natural do homem e, por vezes, a volatilidade da ação? Quais as consequiências desta integração para o processo de trabalho?

\section{A Integração das Características da População}

O trabalho é uma atividade desenvolvida por homens e mulheres, para suprir o que não é determinado pela organização do trabalho. Por isto, não é suficiente o trabalhador seguir somente as prescrições, é necessário interpretar, corrigir, adaptar e às vezes criar. Para atender às exigências da situação de trabalho, ele está constantemente submetido a um processo de regulação interna. A sua inteligência se manifesta ao suprir as lacunas da prescrição e ao transitar pela variabilidade da situação de trabalho, das ferramentas, do objeto de trabalho e da organização real do trabalho.

Ao transitar nestas situações, o trabalhador utiliza estratégias individuais, denominadas modos operatórios, bem como estratégias coletivas, caracterizadas pelo compartilhar da atividade de trabalho com a hierarquia e com os seus pares.

A atividade de um operador de processo contínuo, por exemplo, consiste, basicamente, em obter, processar e armazenar informações oriundas de pontos diferentes, de natureza diversa e de conteúdos distintos. A partir disso, ele constrói seu problema para, posteriormente, agir sobre o funcionamento do processo. Para que esta ação seja eficiente é preciso que ele tenha acesso à uma representação atualizada (tempo real) do estado funcional do sistema.

Esse operador, raramente, age sozinho. Ele confronta seus indicadores e indícios com as representações mentais que outros operadores constróem do processo, para assim efetivar o seu diagnóstico. Nesse sentido, o trabalho de equipe, regulado por um coletivo de trabalho, constitui um dos fatores determinantes para a execução do trabalho. Esse coletivo, se apoia, de um lado, na competência dos operadores e de outro, tão importante quanto o primeiro, nos limites impostos pelas práticas de segurança.

Segundo Vigotsky (1996), um princípio regulatório amplamente difundido no comportamento humano é o da signifi- 
cação, através do qual as pessoas, no contexto de seus esforços para solucionar um problema, criam ligações temporárias e dão significado a estímulos previamente neutros (p. 98).

A competência permite ao indivíduo atribuir um significado para a ação nas situações de trabalho. Segundo Vergnaud (1985), a competência de um indivíduo pressupõe um repertório de procedimentos ou métodos alternativos, que lhe permite se adaptar de forma mais fina às diferentes situações que se apresentam. Isto ocorre em função do valor que ele atribui às diferentes variáveis da situação. Assim, o operador é capaz de adotar o procedimento correto em menor espaço de tempo, com menor custo operacional e de forma menos aleatória, o que lhe permite transitar com maior ou menor grau de dificuldade na diversidade das situações às quais é confrontado. Nessa perspectiva, as competências são descritas do ponto de vista da atividade, possibilitando a compreensão da própria ação.

Se nós admitirmos que toda a ação é inscrita no tempo e que ela sofre evolução contínua, podemos afirmar que a experiência favorece a reconstituição de um novo evento a partir de situações vivenciadas anteriormente. Este fato é o que é visível e passível de formalização. A experiência permite, inclusive, a regulação dos efeitos das más condições do trabalho, na medida em que contribui no processo de antecipação dos incidentes.

Desta forma, ele modifica procedimentos, elabora soluções e avalia alternativas, realizando a gestão de eventuais incidentes que podem ser previstos, evitados, identificados e até corrigidos. Este processo, exige condutas de regulação interna, que podem resultar em aumento da carga de trabalho que varia em função, dentre outros fatores, daqueles decorrentes da experiência.

Assim, a atividade, como fio condutor da análise ergonômica, adota como base de sustentação o fundamento e a gênese das experiências e das competências solicitadas no processo do fazer e que estruturam as tarefas no contexto organizacional.

Quando integramos no projeto de trabalho a noção de variabilidade (experiências, formação) a distância entre o prescrito e o real toma um outro significado, o de campo de atividade de construção de resposta relevante, especialmente no que concerne ao processo de aprendizagem e à melhoria das condições de trabalho. A prescrição polariza uma forma de agir.

A ausência do reconhecimento da interação, entre os planos do trabalho prescrito e do trabalho real, é um fator negativo para a produtividade, pois, além de não favorecer um espaço adequado para o processo de aprendizagem necessária, nega todos os processos de regulação executados pelos operadores quando estes são os meios que permitem aos operadores estabelecerem relações privilegiadas entre as informações presentes no ambiente, suas próprias ações e seus resultados. Neste sentido, a integração dos resultados da análise ergonômica constitui um suporte muito importante para os processos de capacitação/qualificação dos operadores.

A análise ergonômica, quando abordada sob a ótica do processo de aprendizagem e articulada com os diferentes níveis de competência, nos fornece subsídios para a compreensão das exigências de qualificação dos indivíduos, pois permite descrever e explicar as condutas de regulação dos indivíduos, considerando o contexto sociotécnico no qual está inserido.

As competências podem ser analisadas sob dois ângulos, aqueles exigidos pelas tarefas (formalizadas) e aqueles operacionalizados em função das condições reais da realização do trabalho (vivenciadas). Weill-Fassina, Rabardel e Dubois, (1993) chama a atenção para o fato de que o nível de complexidade de uma tarefa para determinado operador depende de sua competência. As abstrações, as antecipações, o tratamento de um número elevado de dados, as interferências e as coordenações, segundo a mesma autora, constituem algumas das dimensões da complexidade das tarefas. A passagem à antecipação é uma atividade de natureza cognitiva, o que significa esquematização, diagnóstico, teste de hipóteses, enfim, abstrações em situação.

A transição do pensamento situacional para o pensamento taxonômico conceitual, segundo Vigotsky, citado por Luria (1994), está relacionada a uma mudança básica no tipo de atividade que o indivíduo está envolvido (p. 70). Ele afirma, no seu trabalho sobre a formação de conceitos, que o "pensamento categorial" e a "orientação abstrata" são consequiências de uma reorganização fundamental da atividade cognitiva que ocorre sob o impacto de um fato novo, social.

A característica principal do pensamento categorial ou abstrato, segundo Luria (1994), está relacionada com a capacidade dos sujeitos transitarem livremente de uma categoria para outra. Já no pensamento concreto ou situacional, os sujeitos classificam os objetos não em categorias lógicas, mas os incorporam às situações gráfico-funcionais reproduzidas de memória.

Vigotsky (1996) distinguiu duas formas fundamentais de experiência que deram origem a dois grupos de conceitos diferentes, contudo interdependentes, o "científico" e o "espontâneo". O grupo dos conceitos "científicos" tem sua origem nas atividades altamente estruturadas e especializadas da instrução escolar e são conceitos logicamente definidos. O grupo dos conceitos "espontâneos" emerge da reflexão do sujeito sobre a sua experiência cotidiana. Os conceitos "espontâneos", segundo Vigotsky, seguem um caminho ascendente em direção a uma maior abstração, delineando assim o caminho para os conceitos científicos no seu desenvolvimento descendente em direção ao concreto.

Nesta perspectiva, distinguimos duas formas possíveis de aprendizagem na formação de conceitos: uma sistematizada pela via da instituição escolar e, a outra, a aprendizagem espontânea, decorrente das vivências do sujeito.

A compreensão destes conceitos quando da introdução de novas tecnologias, é importante, pois torna-se difícil não considerarmos neste processo os conceitos espontâneos dos operadores, quando são submetidos às novas tecnologias. Se tal dinâmica não é considerada, o processo de aprendizagem se inicia tendo como base os conceitos científicos que exigem maior capacidade de abstração. Entretanto, 
quando da introdução de uma nova tecnologia, o processo de formação deve se iniciar tomando como base o repertório oriundo dos "conceitos espontâneos", retidos pela população de trabalhadores, fazendo com que a passagem à abstração seja facilitada. O processo conduzido desta forma permite ao operador transitar do concreto ao abstrato e facilita a elaboração de ligações preferenciais nas situações de resolução de problemas.

Esta possibilidade de abstração contribui favoravelmente para a capacidade de antecipar os incidentes durante o processo, demonstrando, assim, o papel essencial dos operadores para gerir a distância entre o trabalho prescrito e aquele efetivamente realizado. Assim, face a uma situação anormal, os operadores constróem e resolvem problemas de características singulares, mediante processos, muitas vezes de natureza heurística, que combinam uma certa criatividade com anos de experiência socialmente distribuída e compartilhada entre os demais participantes.

Para compreender as modalidades de atividades cognitivas presentes na situação real de trabalho e, eventualmente, transformá-las, é indispensável dispor de um instrumento metodológico que possibilite, especialmente, apreender a forma segundo a qual os operadores constituem os problemas, antes de resolvê-los. A abordagem adotada como referencial neste artigo - a ergonomia, através da metodologia de AET em um sentido mais geral, permite descrever a alternância das fases de constituição e resolução dos problemas, fornecendo parâmetros não só para a transformação de sistemas técnicos, como também para a organização do trabalho, a formação e a transferência de tecnologia.

\section{À Guisa de Conclusão}

Quando integramos as noções de variabilidade, a distância entre o previsto e o realizado toma outro significado, torna-se um fator positivo para a produtividade e incorpora as competências do trabalhador. Segundo Wisner (1987), uma noção muito mais fundamental da organização do trabalho, e muito mais temível em suas consequiências, é a de uma referência tomada sobre um homem médio, bem treinado, que trabalha em um posto estável.

Desvendar o caminho pelo qual o operador constrói os problemas com os quais é confrontado pode constituir uma alternativa para melhor explicar os erros e acidentes do que, simplesmente, identificar as condições sob as quais os problemas são resolvidos. Desta forma, salientamos a contribuição da análise ergonômica do trabalho que pode gerar recomendações nesta direção, pois ela possibilita a compreensão das estratégias de construção do problema, as limitações da organização do trabalho e os elementos a serem incorporadas no treinamento.

Podemos finalizar afirmando que ao assimilarmos e integrarmos a noção de variabilidade, incluímos, também, o dimensionamento dos postos de trabalho, o ritmo biológico, a lateralidade, a antropometria, o ambiente físico, bem como, as estratégias organizacionais adotadas nos projetos industriais/organizacionais.
Assim, compreender a variabilidade, significa repensar a reestruturação do trabalho, resgatando o papel do homem como sujeito desse processo, buscando o equilíbrio entre suas capacidades e seus limites.

\section{Referências}

Abrahão, J. (1996). Ergonomia, Organização do trabalho e aprendizagem. Em UFMG/Dep. Qualidade da Produção, Produção dos homens. (pp. 41-57) Belo Horizonte.

Engeström, Y. (1987). Learning by expanding. Helsinki: OrientaKonsultit.

Laville, A. (1977). Ergonomia. (M.M. Neves Teixeira, Trad.). São Paulo: EPU. (Trabalho original publicado em 1976).

Leontiev, A. (1964). O Desenvolvimento do Psiquismo. São Paulo: Editora Moraes.

Luria, A.R. (1994). O Desenvolvimento Cognitivo. São Paulo: Icone.

Machado, L.R.S. (1994). A educação e os desafios das novas tecnologias. Em C.J. Ferreti (Org.). Novas Tecnologias, trabalho e educação: um debate multidisciplinar. (pp. 169-188). Petropolis: Vozes.

Monoud, P. (1970). Structuration de l'instrument chez l'enfant. Delachaux et Niestlé, Lausanne.

Perrow, C. (1967). A framework for the comparative analysis of organisations. American Sociological Review, 5: 194-208.

Rabardel, P. (1995). Les hommes \& les technologies. Approche cognitive des instruments contemporains. Armand Colin: Paris.

Vergnaud, G. (1985). Concepts et Schèmes dans la théorie operatoire de la représentation. Psychologie Française, 30, 245-252.

Vigotski, L.S. (1996). A formação social da mente. O desenvolvimento dos Processos Psicológicos Superiores. Em M. Cole, V. John-Steiner, S. Scribner \& E. Souberman (Orgs.) (J. Cipola Neto, L.S.M. Barreto \& C.S. Afeche, Trads.) São Paulo: Martins Fontes.

Weill-Fassina, A. (1990). Conduites Cognitives en Situation de Travail. Em Dadoy, M., Henry. C.I., Hillan, B., Tressac, G., Troussier, J.F., Weill-Fassina, A. (Orgs.) Les analyses du travail enjeux et formes. Paris: EREQ.

Weill-Fassina, A., Rabardel, P. \& Dubois, P. (1993). Representations pour l'action. Toulouse: Octares.

Wisner, A. (1987). Por dentro do trabalho: Ergonomia, método e técnica. (F. Gomide Vezza, Trad.) São Paulo: FTD/Oboré.

Wisner, A. (1994a). A inteligência no trabalho: textos selecionados de Ergonomia. (I. Ferreira \& R. Leal, Trads.) São Paulo: Fundacentro.

Wisner, A. (1994b) La cognition et l'action située: conséquences pour l'analyse ergonomique de travail et l'anthropotechnologie. Association canadieenne d'ergonomie, I: 1-13; Ergonomics, 38: 1542-1583.

Wisner, A. (1996). Questions épistémologiques en ergonomie et en analyse du travail. Em: Daniellou, F. (Org.). L'ergonomie en quête de ses principes - Débats épistémologiques. Toulouse: Octarès Editions.

Wisner, A. (1997). Aspects psychologiques de l'anthropotechnologie. Le Travail Humain, 60 (3), 229-254.

Recebido em 14.01.2000

Primeira decisão editorial em 15.02.2000

Versão final em 23.08.2000

Aceito em 10.10.2000 